\title{
Grossman's Missing Health Threshold ${ }^{2}$ t
}

\author{
Titus Galama ${ }^{a,{ }^{*}}$ and Arie Kapteyn ${ }^{a}$ \\ Titus Galama: galama@rand.org; Arie Kapteyn: kapteyn@rand.org \\ aRAND Corporation, 1776 Main Street, P.O. Box 2138, Santa Monica, CA 90407-2138, USA
}

\begin{abstract}
We present a generalized solution to Grossman's model of health capital (1972), relaxing the widely used assumption that individuals can adjust their health stock instantaneously to an "optimal" level without adjustment costs. The Grossman model then predicts the existence of a health threshold above which individuals do not demand medical care. Our generalized solution addresses a significant criticism: the model's prediction that health and medical care are positively related is consistently rejected by the data. We suggest structural- and reduced-form equations to test our generalized solution and contrast the predictions of the model with the empirical literature.
\end{abstract}

\section{Keywords}

health; demand for health; health capital; medical care; labor

\section{Introduction}

Grossman's model of health capital (1972a, 1972b, 2000) is considered a breakthrough in the economics of the derived demand for medical care. In Grossman's human capital framework individuals demand medical care (e.g., invest time and consume medical goods and services) for the consumption benefits (health provides utility) as well as production benefits (healthy individuals have greater earnings) that good health provides. The model has been employed widely to explore a variety of phenomena related to health, medical care, inequality in health, the relationship between health and socioeconomic status, occupational choice, etc (e.g., Muurinen and Le Grand, 1985; Case and Deaton, 2005; Cropper, 1977).

Yet the Grossman model has also received significant criticism. For example, the model has been criticized for its simplistic deterministic nature (e.g., Cropper, 1977; Dardanoni and Wagstaff, 1987), for not determining length of life (e.g., Ehrlich and Chuma, 1990), for allowing complete health repair (Case and Deaton, 2005), and for its formulation in which medical investment in health has constant returns which is argued to lead to an unrealistic "bang-bang" solution (e.g., Ehrlich and Chuma, 1990). The criticism has led to theoretical

\footnotetext{
This research was supported by the National Institute on Aging, under grants R01AG030824, R01AG037398, P30AG012815 and P01AG022481. We are grateful to Arthur van Soest, Eddy van Doorslaer, Hans van Kippersluis, Erik Meijer, Raquel Fonseca, PierreCarl Michaud and James Hosek for useful discussions and comments.

(C) 2011 Elsevier B.V. All rights reserved.

*Corresponding author; phone: +1 (310) 393-0411 × 6057; fax: +1 (310) 260-8158.

Publisher's Disclaimer: This is a PDF file of an unedited manuscript that has been accepted for publication. As a service to our customers we are providing this early version of the manuscript. The manuscript will undergo copyediting, typesetting, and review of the resulting proof before it is published in its final citable form. Please note that during the production process errors may be discovered which could affect the content, and all legal disclaimers that apply to the journal pertain.
} 
and empirical extensions of the model, which to a large extent address the issues identified. ${ }^{1}$ For an extensive review see Grossman (2000) and the work referenced therein.

However, there is one significant criticism that thus far has not satisfactorily been addressed. Zweifel and Breyer (1997; p. 62) reject the model's central proposition that the demand for medical care is derived from the demand for good health: “... the notion that expenditure on medical care constitutes a demand derived from an underlying demand for health cannot be upheld because health status and demand for medical care are negatively rather than positively related ..." In a review of the empirical literature Zweifel and Breyer conclude that the model's prediction that health and medical care should be positively related (healthy individuals consume more medical goods and services) is consistently rejected by the data. For example, Cochrane et al. (1978) find in a study of various determinants of mortality across various countries that indicators of medical care usage are positively related to mortality. And more specifically, Wagstaff (1986) and Leu and Gerfin (1992), in estimating structural- and reduced-form equations of the Grossman model, find that measures of medical care are negatively correlated with measures of health and that the relationships are highly significant.

Several authors have sought to explain the consistently negative relation between health and medical care in empirical studies. For example, Grossman argues that the observed negative relation could be attributed to biases that arise if the conditional demand function is estimated with health treated as exogenous (Grossman, 2000; p. 386). Further, Grossman (2000; pp. 369-370) shows that the model does not always produce the incorrect sign for the relationship between health and investment in medical care. For the pure investment model and assuming that the "natural" deterioration rate increases with age (a necessary assumption for the health stock to decline with age in Grossman's formulation), Grossman finds that investment in medical care increases with age while the health stock falls with age if the elasticity of the marginal production benefit of health with respect to health is less than one (Grossman refers to this as the MEC schedule). Thus it is the relation between earnings and health (the marginal production benefit of health or MEC schedule) that is responsible for the observed negative relation.

Muurinen and Le Grand (1985), in attempting to explain the positive relation between mortality and medical care usage found by Cochrane et al. (1978), suggest that the negative relation between indicators of health and of medical care (apart from suggesting that medical care is actually harmful) could be explained by differences in socioeconomic status. Individuals with fewer resources derive relatively higher production benefits from their health stock. They thus would have relatively greater usage of the stock (i.e., higher rates of health deterioration) which would require higher medical care to compensate for health losses. But if health cannot be completely repaired due to the increased use-intensity they would have inferior health states. High mortality would then be positively correlated with use of health services.

Wagstaff (1986) provides a detailed discussion of potential reasons why estimates of the Grossman model may lead to a negative relation between measures of medical care usage and measures of health. On the one hand, one might argue that the coefficients determined in Wagstaff (1986) and similar analyses are not reliable estimates of the model's parameters. For example, Wagstaff suggests that in moving from the theoretical to the empirical model inappropriate assumptions may have been introduced (see Wagstaff, 1986, for details). Or the identification of medical care with market inputs may insufficiently characterize health

${ }^{1}$ With the exception perhaps of the "bang-bang" solution and for allowing complete health repair, which we will discuss briefly in this work. 
inputs if non-medical inputs are important in the production of health. On the other hand, one may take the estimates at face value and seek explanations in terms of the underlying model. Interestingly, Wagstaff (1986) suggests that, contrary to what is assumed in Grossman's theoretical work, the negative relationship may reflect a non-instantaneous adjustment of health capital to its "optimal" value. This, Wagstaff argues, may be the result of a constraint on medical care or be due to the existence of adjustment costs. Wagstaff finds in subsequent analysis (Wagstaff, 1993) that a reformulation of Grossman's empirical model with non-instantaneous adjustment is not only more consistent with Grossman's theoretical model but also with the data.

Indeed, in earlier theoretical work building on a simplified version of the Grossman model (Galama et al. 2009) we concluded that the widely employed assumption in the Grossman literature that any health "excess" or "deficit" can be adjusted instantaneously and at no adjustment cost may be too restrictive. Any "excess" in health capital cannot rapidly dissipate as individuals with "excessive" health can at best decide not to consume medical care. As a consequence their health deteriorates at the natural deterioration rate $d(t)$ (i.e., non instantaneous) until health reaches Grossman's "optimal" level. Thus an individual's health is not always at the predicted "optimal" level. While the widely employed assumption that an individual's health follows Grossman's solution for the "optimal" path allows one to derive simple model predictions for empirical validation (and indeed this may be the primary reason for its use), it is otherwise unnecessary and is not demanded by theory. Importantly, Wagstaff's (1993) work suggests that individuals do not adjust their health stocks instantaneously. In other words, not only is there no theoretical basis for the assumption, empirical evidence suggests the assumption is not valid.

In this paper we relax the widely used assumption that individuals can adjust their health stock to Grossman's "optimal" level instantaneously. We do not restrict an individual's health path to Grossman's "optimal" solution but allow for corner solutions where the optimal response for healthy individuals is to not consume medical goods and services for some period of time.

We then find that the Grossman model predicts a substantially different pattern of medical care over the life-time than previously was assumed. Healthy individuals initially do not demand medical care untill their health has deteriorated to a certain threshold level given by Grossman's "optimal" health. Subsequently their health evolves as the Grossman solution for the "optimal" path as individuals begin to demand medical care. In other words, Grossman's "optimal" health level is in fact a "health threshold" rather than an "optimal" trajectory. Grossman's model thus predicts that healthy individuals demand less medical care, not the opposite, in agreement with the empirical literature. Further, as we will see, this hypothesis can explain a number of other empirical facts.

We proceed as follows. In section 2, we reformulate the Grossman model in continuous time allowing for corner solutions, solve the optimal control problem and derive first-order conditions for consumption and health. In section 3 we present structural-form and reducedform solutions for health, medical care and consumption to enable empirical testing of our reformulation of the Grossman model. In section 4 we contrast the predictions of our generalized solution of the Grossman model with the traditional solution and with the empirical literature. We conclude in section 5. Detailed derivations can be found in the Appendix.

\section{General framework: the full Grossman model}

We present the original human-capital model of the derived demand for health by Grossman (Grossman, 1972a, 1972b, 2000) in continuous time (see also Wagstaff, 1986; Wolfe, 1985; 
Zweifel and Breyer, 1997; Ehrlich and Chuma, 1990). Health is treated as a form of human capital (health capital) and individuals derive both consumption (health provides utility) and production benefits (health increases earnings) from it. The demand for medical care is a derived demand: individuals demand "good health", not the consumption of medical care. In the original formulation of the Grossman model (Grossman, 1972a, 1972b, 2000) health yields an output of healthy time and consumption and medical care constitute both own-time inputs and goods or services purchased in the market. Simplified versions of the Grossman model have been presented by Case and Deaton (2005) who assume consumption and production benefits are functions of health rather than healthy time, Wolfe (1985) who assumes health does not provide utility, and Case and Deaton (2005) who do not include time inputs into the production of consumption nor in the production of medical care. For an excellent review of the basic concepts of the Grossman model see Muurinen and Le Grand (1985).

Individuals maximize the life-time utility function

$$
\int_{0}^{T} U[C(t), H(t)] e^{-\beta t} d t
$$

where $T$ denotes total life time, $\beta$ is a subjective discount factor and individuals derive utility $U[C(t), H(t)]$ from consumption $C(t)$ and from health $H(t) .{ }^{2}$ Time $t$ is measured from the time individuals begin employment. Utility increases with consumption $\partial U(t) / \partial C(t) \geq 0$ and with health $\partial U(t) / \partial H(t) \geq 0$. Further we assume diminishing marginal benefits: $\partial^{2} U(t) /$ $\partial^{2} C(t) \leq 0$ and $\partial^{2} U(t) / \partial^{2} H(t) \leq 0$.

The objective function (1) is maximized subject to the following constraints:

$$
\begin{gathered}
\dot{H}(t)=I(t)-d(t) H(t), \\
\dot{A}(t)=\delta A(t)+Y[H(t)]-p_{X}(t) X(t)-p_{m}(t) m(t),
\end{gathered}
$$

and we have initial and end conditions: $H(0), H(T), A(0)$ and $A(T)$ are given.

$\dot{H}(t)$ and $\dot{A}(t)$ in equations (2) and (3) denote time derivatives of health $H(t)$ and assets $A(t)$. Health (equation 2) can be improved through medical health investment $I(t)$ (medical care) and deteriorates at the "natural" health deterioration rate $d(t)$. Using equation (2) we can write $H(t)$ as a function of medical care $I(t)$ and initial health $H(0)$,

\footnotetext{
${ }^{2}$ Grossman (1972a, 1972b, 2000) formulates his model in terms of sick time and assumes that sick time $s(t)$ is a function of health $H(t) ; s(t)=s[H(t)]$. One possible reason for this formulation is that the NORC data set the author employed in empirical testing of the model contained information on sick days. An alternative formulation is provided by Case and Deaton (2005). Case and Deaton formulate a simplified Grossman model in which utility and income are functions of health $H(t)$ directly, rather than indirectly through sick-time $s(t)$. Following Case and Deaton we write utility $U\{C(t), s[H(t)]\}=U[C(t), H(t)]$ and income $Y\{s[H(t)]\}=Y[H(t)]$ as functions of health $H(t)$ instead of sick time $s(t)$. Essentially both formulations are equivalent except that Case and Deaton's formulation is more general, allowing for example for earnings to be influenced not only by reductions in sick time but also increased worker efficiency resulting from good health.
} 


$$
H(t)=H(0) e^{-\int_{0}^{t} d(s) d s}+\int_{0}^{t} I(x) e^{-\int_{x}^{t} d(s) d s} d x
$$

Assets $A(t)$ (equation 3 ) provide a return $\delta$ (the interest rate), increase with income $Y[H(t)]$ and decrease with purchases in the market of goods $X(t)$ and medical goods and services $m(t)$ at prices $p_{X}(t)$ and $p_{m}(t)$, respectively. Income $Y[H(t)]$ is assumed to be an increasing function of health $H(t)$.

Integrating equation (3) over the life time we obtain the life-time budget constraint

$\int_{0}^{T} p_{X}(t) X(t) e^{-\delta t} d t+\int_{0}^{T} p_{m}(t) m(t) e^{-\delta t} d t=A(0)-A(T) e^{-\delta T}+\int_{0}^{T} Y\{s[H(t)]\} e^{-\delta t} d t$

The left-hand side of (5) represents life-time consumption of market goods and life-time consumption of medical goods and services, and the right-hand side represents life-time financial resources in terms of life-time assets and life-time earnings.

Goods $X(t)$ purchased in the market and own time inputs $\tau_{C}(t)$ are used in the production of consumption $C(t)$. Similarly medical goods and services $m(t)$ and own time inputs $\tau_{I}(t)$ are used in the production of medical care $I(t)$. The efficiencies of production are assumed to be a function of the consumer's stock of knowledge $E$ (an individual's human capital exclusive of health capital [e.g., education]) as it is generally believed that the more educated are more efficient consumers of medical care (see, e.g., Grossman, 2000),

$$
I(t)=I\left[m(t), \tau_{I}(t) ; E\right]
$$

$$
C(t)=C\left[X(t), \tau_{C}(t) ; E\right] .
$$

The total time available in any period $\Omega$ is the sum of all possible uses $\tau_{w}(t)$ (work), $\tau_{I}(t)$ (medical care), $\tau_{C}(t)$ (consumption) and $s[H(t)]$ (sick time),

$$
\Omega=\tau_{w}(t)+\tau_{I}(t)+\tau_{C}(t)+s[H(t)]
$$

In this formulation one can interpret $\tau_{C}(t)$, the own-time input into consumption $C(t)$ as representing leisure.

Income $Y[H(t)]$ is taken to be a function of the wage rate $w(t)$ times the amount of time spent working $\tau_{w}(t)$,

$$
Y[H(t)]=w(t)\left\{\Omega-\tau_{I}(t)-\tau_{C}(t)-s[H(t)]\right\}
$$

So far we have simply followed Grossman's formulation in continuous time. See Wagstaff (1986), Wolfe (1985), Zweifel and Breyer (1997), and Ehrlich and Chuma (1990) for similar 
formulations. Our formulation differs however in one crucial respect from prior work: we explicitly impose the constraint that medical care is non-negative for all ages and allow for corner solutions in which individuals do not demand medical care $(I(t)=0)$.

\subsection{Periods where individuals do not demand medical care: $I(t)=0$}

It is commonly assumed that any initial "excess" in health capital can be shed and any "deficit" can be repaired over a small period of time and at negligible cost. In other words, individuals are capable of ensuring that their health is at a certain desirable or "optimal" level (e.g., Grossman, 1972a, 1972b, 2000; Case and Deaton, 2005; Muurinen, 1982; Wagstaff, 1986; Zweifel and Breyer, 1997; Ried, 1998). This assumption is not necessarily always stated explicitly. The literature generally assumes that there are no corner solutions. In making this assumption the literature restricts the solution to Grossman's "optimal" solution. While this allows one to derive simple model predictions for empirical validation, it is unnecessary.

Healthy individuals, those with health levels above the "optimal" level, may desire to substitute health capital for more liquid capital. In other words, individuals may wish to "sell" their health. But, as equation (4) shows individuals cannot "choose" health optimally. Instead they can consume medical care (medical health investment) $I(t)$ optimally. But medical care $I(t)$, viewed as health-promoting cannot be traded (individuals cannot "sell" health through negative medical health investment) and is therefore positive for all ages $I(t)$ $\geq 0$. As a result health cannot deteriorate faster than the health deterioration rate $d(t)$. This corresponds to the corner solution $I(t)=0$.

Thus, we have the following optimal control problem: the objective function (1) is maximized with respect to the control functions $C(t)$ and $I(t)$ and subject to the constraints (2 and 3). The Lagrangean or generalized Hamiltonian (see, e.g., Seierstad and Sydsaeter, 1987) of this problem is:

$\mathfrak{J}=U[C(t), H(t)] e^{-\beta t}+q_{H}(t)\{I(t)-d(t) H(t)\}+q_{A}(t)\left\{\delta A(t)+Y[H(t)]-p_{X}(t) X(t)-p_{m}(t) m(t)\right\}+q_{i}(t) I(t)$,

where $q_{H}(t)$ is the adjoint variable associated with the differential equation (2) for health $H(t), q_{A}(t)$ is the adjoint variable associated with the differential equation (3) for assets $A(t)$, and $q_{I}(t)$ is a multiplier associated with the condition that health investment is non negative, $I(t) \geq 0$.

\subsection{First-order conditions}

The first-order condition for maximization of (1) with respect to consumption, subject to the conditions (2) and (3) is

$$
\partial U(t) / \partial C(t)=q_{A}(0) \pi_{C}(t) e^{(\beta-\delta) t},
$$

where the Lagrange multiplier $q_{A}(0)$ is the shadow price of wealth (see, e.g., Case and Deaton, 2005) and $\pi_{C}(t)$ is the marginal cost of consumption $C(t)$

$$
\pi_{C}(t) \equiv \frac{p_{X}(t)}{\partial C(t) / \partial X(t)}=\frac{w(t)}{\partial C(t) / \partial \tau_{C}(t)} .
$$


The first-order condition for maximization of (1) with respect to health investment, subject to the conditions (2) and (3) is

$$
\frac{\partial U(t)}{\partial H(t)} \equiv q_{A}(0)\left[\pi_{H}(t)-\varphi_{H}(t)\right] e^{(\beta-\delta) t}+\left[\dot{q}_{I}(t)-q_{I}(t) d(t)\right] e^{\beta t}
$$

where $\pi_{H}(t)$ is the user cost of health capital at the margin,

$$
\pi_{H}(t) \equiv \pi_{I}(t)\left[d(t)+\delta-\tilde{\pi}_{I}(t)\right],
$$

$\pi_{I}(t)$ is the marginal cost of medical health investment $I(t)$ (see equation 10 in Grossman, 2000)

$$
\pi_{I}(t) \equiv \frac{p_{m}(t)}{\partial I(t) / \partial m(t)}=\frac{w(t)}{\partial I(t) / \partial \tau_{I}(t)}
$$

$\tilde{\pi}_{I}(t) \equiv \dot{\pi}_{I}(t) / \pi_{I}(t)$ and $\varphi_{H}(t)$ is the marginal production benefit of health

$$
\varphi_{H}(t) \equiv \frac{\partial Y(t)}{\partial H(t)}
$$

Note that we have to impose that the user cost of health capital at the margin exceeds the marginal production benefits of health $\pi_{H}(t)>\varphi_{H}(t)$. Without this condition, the consumption of medical care would finance itself by increasing earnings by more than the user cost of health. As a result of this, consumers would choose infinite medical care paid for by infinite earnings increases to reach infinite health.

Equations (11) and (13) describe the first-order conditions for the constrained optimization problem. Equation (11) is similar to equation 4a by Wagstaff (1986) and equation 6 by Case and Deaton (2005). Equation (13) is similar to equations 13, 1-13 and 11 of Grossman (1972a), (1972b) and (2000), respectively, equation 4b by Wagstaff (1986), equation 3.5 of Zweifel and Breyer (1997), and equation 6 by Case and Deaton (2005), for $q_{I}(t)=0$ (i.e., $I(t)$ $>0) .{ }^{3}$ The essential difference between our results and those of the aforementioned authors is in the term $q_{I}(t)$ which is non-vanishing for $I(t)=0$.

\subsection{Grossman's solutions for consumption and health}

The first-order condition (13) contains an expression in the multiplier $q_{I}(t)$ which is nonvanishing $\left(q_{I}(t)=0\right)$ for corner solutions in which individuals do not demand medical care $(I(t)=0)$. Let's first focus on the solution where $q_{I}(t)=0$. This special case corresponds to the solutions found by Grossman (1972a, 1972b, 2000). The first-order condition (13) determines the "optimal" level of health for the "traditional" solution, which we denote by $H *(t)$.

\footnotetext{
${ }^{3}$ Various other authors have presented first-order conditions for the Grossman model. The list provided here is not exhaustive.
} 
The marginal benefit of health (equation 13) equals the product of the shadow price of wealth $q_{A}(0)$, the user cost of health capital at the margin $\pi_{h}(t)$ minus the marginal production benefit of health $\varphi_{H}(t)$, and a time varying term with exponent $(\beta-\delta) t$. Since the marginal benefit of health $\partial U(t) / \partial H(t)$ is a decreasing function in health $H(t)$, lower lifetime resources (i.e., higher $\left.q_{A}(0)\right)^{4}$, higher user cost of health capital $\pi_{H}(t)$ and lower production benefits of health $\varphi_{H}(t)$ will lower the "optimal" level of health $H_{*}(t)$. The user cost of health capital (see equations 14 and 15) increases with the price $p_{m}(t)$ of medical goods/services, with wages $w(t)$, the health deterioration rate $d(t)$ and the rate of return on assets $\delta$ (reflecting an opportunity cost). The user cost of health capital decreases with the efficiency of medical goods/services in producing medical care, $\partial I(t) / \partial m(t)$, the efficiency of time input $\tau_{I}(t)$ in producing medical care, $\partial I(t) / \partial \tau_{I}(t)$, and with $\pi_{I}(t)$, the rate of relative change in the marginal cost of medical care $\pi_{I}$. The marginal production benefit of health $\varphi_{H}(t)$ (equation 16) increases with the extent to which health increases earnings $\partial Y(t) / \partial H(t)$.

A lower price of medical goods/services thus increases health. This is pertinent in a crosscountry comparison, but also when comparing across the life-cycle, for instance if health care is subsidized for certain age groups (like Medicare in the U.S.) Also, more efficient medical care will lead to greater health. Efficiency can explain variations within a country (if for instance individuals with a higher education level are more efficient consumers of medical care, Goldman and Smith, 2002) or across countries (if health care is more efficient in one country than in another).

The first-order condition (11) determines the level of consumption $C(t)$. It requires the marginal benefit of consumption to equal the product of the shadow price of wealth $q_{A}(0)$, the marginal cost of consumption $\pi_{C}(t)$, and a time varying exponent that either grows or decays with time, depending on the difference $\beta-\delta$ between the time preference rate $\beta$ and the interest rate $\delta$. Increasing lifetime resources will lower $q_{A}(0)$ and hence increase consumption. The marginal cost of consumption $\pi_{C}(t)$ increases with the price $p_{X}(t)$ of consumption goods $X(t)$ and with wages $w(t)$, and decreases with the efficiency of consumption goods in producing consumption, $\partial C(t) / \partial X(t)$ and with the efficiency of time inputs $\tau_{C}(t)$ in producing consumption, $\partial C(t) / \partial \tau_{C}(t)$ (see equation 12). Since the marginal benefit of consumption $\partial U(t) / \partial C(t)$ is a decreasing function of consumption $C(t)$, higher prices of consumption goods $p_{X}(t)$, higher wages $w(t)$ and lower efficiencies $\partial C(t) / \partial X(t)$ and $\partial C(t) / \partial \tau_{C}(t)$ lower the equilibrium level of consumption $C(t)$.

\subsection{Corner solutions}

We allow for corner solutions in which individuals do not demand medical care $I(t)=0$. This situation occurs when individuals have initial health endowments $H(0)$ that are greater than Grossman's "optimal” level of health $H_{*(0)}$.

We follow a simple intuitive approach. The corner solution is associated with a nonvanishing Lagrange multiplier $q_{I}(t)$. The solution for consumption is still provided by the first-order condition (11) as this condition is independent of the Lagrange multiplier $q_{I}(t)$. The solution for medical care is simply

$$
I(t)=0 .
$$

\footnotetext{
${ }^{4}$ This result can be obtained by substituting the solutions for consumption, health, and medical care in the budget constraint (equation 5) and solving for $q_{A}(0)$. See, for example, Galama et al. (2009).
} 
We do not need to use the first-order condition (13) to obtain the solution for health. Using equation (4) and $I(x)=0$ we have

$$
H(t)=H(0) e^{-\int_{0}^{t} d(s) d s} .
$$

In other words, in the absence of medical care health deteriorates at the natural deterioration rate $d(t)$. The corner solution is fully determined by equations (11), (17) and (18).

\section{Empirical model}

Wolfe (1985) assumes an initial surplus of health and is, to the best of our knowledge, the only researcher who has attempted to explore the consequences of corner solutions in Grossman's model in some detail. Wolfe employs a simplified Grossman model where health (or, alternatively, reduced sick time as in Grossman's original formulation) does not provide utility. Wolfe interprets the onset of " ... a discontinuous mid-life increase in health investment ..." with retirement. We however do not associate the discontinuous increase in medical health investment with retirement but with becoming unhealthy (health levels at the health threshold leading to consumption of medical care to improve health). We allow the onset of medical health investment to take place anytime during the life of individuals, including allowing for the possibility that the onset never occurs. While Wolfe (1985) provides a convincing argument that high initial health endowments are plausible ${ }^{5}$, we simply assume that initial health $H(0)$ can take any positive value (including values below the health threshold).

We distinguish three scenarios as shown in figure 1 . We show the simplest case in which the health threshold $H_{*}(t)$ is constant across age (e.g., for constant user cost of health capital $\pi_{h}(t)=\pi_{H}(0)$, constant production benefits of health $\left(\varphi_{H}(t)=\varphi_{h}(0)\right.$ and for $\beta=\delta$; see equations 11 and 13) but the scenarios are valid for more general cases. Scenarios A and B begin with initial health $H(0)$ greater than the initial health threshold $H_{*}(0)$ and scenario C begins with initial health $H(0)$ below the initial health threshold $H_{*}(0)$. In scenario A health $H(t)$ reaches the health threshold $H_{*}(t)$ during life (before the age of death $T$ ) at age $t_{1}$. In scenario B health $H(t)$ never reaches the health threshold $H *(t)$ during the life of the individual. In scenario $\mathrm{C}$ individuals begin working life with health levels $H(0)$ below the initial health threshold $H_{*}(0)$.

In scenarios $\mathrm{A}$ and $\mathrm{B}$ the solution for health is determined by the corner solution presented in section 2.4 for young ages (scenario A) or all ages (scenario B). In scenario A, after health reaches the threshold level the solutions are determined by the "traditional" Grossman solution. In scenarios A and B we do not have to assume that individuals adjust their health to reach the health threshold.

In contrast, in scenario $\mathrm{C}$ we follow the traditional Grossman model and assume that an individual is able to adjust his/her health level to reach the health threshold ("optimal" health). Individuals will invest a portion of initial assets $A(0)$ to improve initial health $H(0)$

\footnotetext{
${ }^{5}$ On the grounds that “... the human species, with its goal of self-preservation, confronts a different problem than the individual who seeks to maximize utility. The evolutionary solution to the former may entail an excessive health endowment in the sense that an individual might prefer to have less health and to be compensated with wealth in a more liquid form ..." In other words, humans may have been endowed with "excessive" health as a result of our evolutionary history which required good physical condition to hunt and gather food, defend ourselves, survive periods of hunger etc. Today's demands on human's physical condition are essentially based on the utility of good health and on economic productivity, which in an increasingly knowledge-intensive environment may be significantly smaller than in pre-historic times.
} 
such that initial health equals the initial health threshold $H(0)=H *(0)$. These solutions have been criticized by Ehrlich and Chuma (1990) as being unrealistic "bang-bang" solutions; the adjustment takes place instantaneously. Our working hypothesis is, however, that most individuals are healthy for most of their life (health levels above the health threshold). A consequence of this is that scenario $\mathrm{C}$, where initial health is below the initial health threshold, is less relevant for our discussion.

Following Grossman (1972a, 1972b, 2000) and Wagstaff (1986) we derive structural- and reduced-form equations for empirical testing. Empirical tests of Grossman's model in the empirical literature have been based on estimating two sub-models (1) the "pure investment" model in which the restriction $\partial U(t) / \partial H(t)=0$ is imposed and (2) the "pure consumption" model in which the restriction $\partial Y(t) / \partial H(t)=0$ is imposed. To allow comparison with previous research we adopt the same restrictions and explore the same two sub-models. As Wagstaff (1986) notes equation (13) can be transformed into a linear estimating equation with the restriction $\partial U(t) / \partial H(t)=0$ or $\partial Y(t) / \partial H(t)=0$, but this is not the case for the more general model. In addition, without imposing these restrictions analytical solutions for health, medical care and consumption cannot be obtained without making further assumptions. Lastly, the two sub models represent two essential characteristics of health: health as a means to produce (investment) and health as a means to provide utility (consumption). We now discuss each sub-model in turn. Variables and functions that we use throughout the paper are tabulated and defined in Table 1.

\subsection{Pure investment model}

In the following we follow Grossman (1972a, 1972b, 2000). We impose $\partial U(t) / \partial H(t)=0$, and assume that sick time is a power law in health

$$
s(t)=\beta_{0}+\beta_{1} H(t)^{-\beta_{2}},
$$

where $\beta_{1}$ and $\beta_{2}$ are positive constants (e.g., Wagstaff, 1986). ${ }^{6}$ We thus have

$$
\partial Y(t) / \partial H(t)=\beta_{1} \beta_{2} w(t) H(t)^{-\left(\beta_{2}+1\right)} .
$$

We further assume that health investment (medical care) is produced by combining own time and medical goods/services according to a Cobb-Douglass constant returns to scale production function

$$
I(t)=\mu_{l}(t) m(t)^{1-k_{l}} \tau_{l}(t)^{k_{l}} e^{\rho_{I} E},
$$

where $\mu_{I}(t)$ is an efficiency factor, $1-k_{I}$ is the elasticity of medical care $I(t)$ with respect to medical goods/services $m(t), k_{I}$ is the elasticity of medical care $I(t)$ with respect to health time input $\tau_{I}(t)$, and $p_{I}$ determines the extent to which education $E$ improves the efficiency of medical care $I(t)$. Further, we have (see equation 15)

\footnotetext{
${ }^{6} \mathrm{But}$ note that negative values can be allowed as long as $\beta_{1} \beta_{2}>0$
} 


$$
\frac{\partial I(t) / \partial m(t)}{\partial I(t) / \partial \tau_{I}(t)}=\frac{p_{m}(t)}{w(t)}=\frac{1-k_{I}}{k_{I}} \frac{\tau_{I}(t)}{m(t)}
$$

Lastly, we follow Wagstaff (1986) and Cropper (1981) and assume the health deterioration rate $d(t)$ to be of the form

$$
d(t)=d_{\bullet} e^{\beta_{3} t+\beta_{4} \mathrm{X}(\mathbf{t})},
$$

where $d . \equiv d(0) e^{-\beta_{4} \mathbf{X}(0)}$ and $\mathbf{X}(t)$ is a vector of environmental variables (e.g., working and living conditions, hazardous environment, etc) that affect the deterioration rate. The vector $\mathbf{X}(t)$ may include other exogenous variables that affect the deterioration rate, such as education (Muurinen, 1982).

\subsubsection{Health threshold}

Structural-form equations: The health "threshold" describes the health trajectory in scenario $\mathrm{C}$ and in scenario A after age $t_{1}$ (see Figure 1). The structural-form equation for the health "threshold" is as follows

$$
\begin{aligned}
\ln H(t)= & \beta_{5}+\varepsilon\left(1-k_{1}\right) \ln w(t) \\
& -\varepsilon\left(1-k_{l}\right) \ln p_{m}(t) \\
& +\varepsilon \rho_{l} E \\
& -\varepsilon\left(\beta_{3}+\beta_{6}\right) t \\
& -\varepsilon \beta_{4} \mathrm{X}(\mathbf{t}) \\
& -\varepsilon \ln d \bullet \\
& -\varepsilon \ln \left\{1+d_{\bullet}^{-1} e^{-\beta_{3} t-\beta_{4} \mathrm{X}(\mathbf{t})}\left[\delta-k_{1} \tilde{w}(t)-\left(1-k_{l}\right) \tilde{p}_{m}(t)-\beta_{6}\right]\right\},
\end{aligned}
$$

where $\varepsilon \equiv\left(\beta_{2}+1\right)^{-1}$, the constant $\beta_{5} \equiv \varepsilon \ln \left(\beta_{1} \beta_{2}\right)+\varepsilon \ln \left[k_{I}^{k_{I}}\left(1-k_{l}\right)^{\left(1-k_{I}\right)}\right]+\varepsilon \ln \mu_{l}(0)$, and we allow medical technology $\mu_{l}(t)=\mu_{l}(0) e^{-\beta_{6} t}$ to depend on age (e.g., the efficiency of medical goods/services $m(t)$ and own time inputs $\tau_{I}(t)$ in improving health could diminish with age). ${ }^{7}$ It is customary to assume that the term $\ln d$. in equation (24) is an error term with zero mean and constant variance $\xi_{1}(t)=-\ln d$. (as in Wagstaff, 1986, and Grossman, 1972a, $1972 \mathrm{~b}, 2000)$ and that the term $\operatorname{In}\left[1+\delta / d(t) \tilde{\pi}_{I}(t) / d(t)\right]$ (the last term in equation 24$)$ is small or constant (see, e.g., Grossman, 1972a, 2000), ${ }^{8}$ or that it is time dependent $\operatorname{In}\left[1+\delta / d(t) \tilde{\pi}_{I}(t) /\right.$ $d(t)] \alpha(t)$ (e.g, Wagstaff, 1986). We do not have to make these assumptions as in our generalized solution of the Grossman model the rate of deterioration $d(t)$ is observable for those times that individuals do not demand medical care (i.e., for corner solutions). While we assume that the last term in equation (24) is small, our formulation allows us to estimate and test this common assumption.

The demand for health (equation 24) thus increases with wages $w(t)$ and with education $E$ and decreases with prices $p_{m}(t)$ and the health deterioration rate (terms $d_{\bullet}, \beta_{3}$ and $\beta_{4} \mathbf{X}(t)$ ).

\footnotetext{
${ }^{7}$ For example, elderly and frail patients may not be able to cope with certain aggressive chemotherapy regiments. Note also that advances in medical technology could be modeled by an increasing $\mu_{I}(0)$ with time (e.g., $\mu_{I}(0)$ increases with subsequent cohorts). ${ }^{8}$ This would require that the real interest rate $\delta$ and changes in the ratio of the price of medical goods/services and the efficiency of medical goods/services in producing medical care $\pi_{I}(t)=p_{m}(t) /[\partial I(t) / \partial m(t)]$ are much smaller than the health deterioration rate $d(t)$ or that changes in the interest rate and in $\tilde{\pi}_{I}(t)$ follow the same pattern as changes in $d(t)$ (so that the term is approximately constant).
} 
The relation with age $t$ is ambiguous. To ensure that health declines with age, it is commonly assumed that health deterioration increases with age, $\dot{d}(t)>0$ (i.e. that $\beta_{3}>0$ ). ${ }^{9}$ But since wages $w(t)$ generally increase with years of experience (e.g., Mincer, 1974) it is possible that the health threshold initially increases with age $t$.

The structural equation for the "optimal" consumption of medical goods/services is as follows

$\ln m(t)=\beta_{7}+\ln H(t)+k_{I} \ln w(t)-k_{I} \ln p_{m}(t)-\rho_{I} E+\left(\beta_{3}+\beta_{6}\right) t+\beta_{4} \mathbf{X}(\mathbf{t})+\ln \mathbf{d}_{\bullet}+\ln \left[\mathbf{1}+\tilde{\mathbf{H}}(\mathbf{t}) \mathbf{d}_{\bullet}^{-1} \mathbf{e}^{-\beta_{3} \mathbf{t}-\beta_{4} \mathbf{X}(\mathbf{t})}\right]$,

Where $\beta_{7} \equiv-\ln \mu_{I}(0)-k_{I} \ln \left[k_{I} /\left(1-k_{I}\right)\right]$. It is customary to assume that the last term in equation $(25), \ln [1+\tilde{H}(t) / d(t)]=\ln \left[1+\tilde{H}(t) d_{\bullet}^{-1} e^{-\beta_{3} t-\beta_{4} \mathrm{X}(\mathrm{t})}\right]$, is small and can be ignored (Grossman, 1972b) or treated as an error term (Wagstaff, 1986). This would require that the effective rate of change in health $\dot{H}(t)$ is smaller than $d(t) H(t)$. This assumption is perhaps not unreasonable if medical care is efficient and slows down the effective health decline $\dot{H}(t)$. For small $\tilde{H(t)} / d(t)$, we have $\operatorname{In}[1+\tilde{H(}(t) / d(t)] \sim \tilde{H(t)} / d(t)$.

Equation (25) predicts that Grossman's "optimal” demand for medical goods/services and Grossman's "optimal" demand for health are positively related. This is the crucial prediction which empirical studies consistently reject. Further, the demand for medical goods/services increases with wages $w(t)$ and the health deterioration rate (terms $d_{\bullet}, \beta_{3}$ and $\beta_{4} \mathbf{X}(t)$ ), and decreases with education $E$ and prices $p_{m}(t)$.

The literature usually focuses on the equations for health (24) and medical care (25), but note that equation (11) provides a condition for consumption $C(t)$ as well, which can be utilized to obtain expressions for consumption goods $X(t)$. The budget constraint (equation 3 ) then provides the solution for assets $A(t)$.

Reduced-form equations: Wagstaff (1986) notes that one way of overcoming the unobservability of health capital is to estimate reduced-form demand functions for health and medical goods/services. Combining (24) and (25) and eliminating any expression in health $H(t)$ we find:

$$
\begin{aligned}
\ln m(t)= & \beta_{8}+\left[k_{l}+\varepsilon\left(1-k_{l}\right)\right] \ln w(t)-\left[k_{I}+\varepsilon\left(1-k_{I}\right)\right] \ln p_{m}(t) \\
& -(1-\varepsilon) \rho_{I} E-\varepsilon\left[\beta_{3}-(1-\varepsilon) \beta_{6}\right] t-\varepsilon \beta_{4} \mathrm{X}(\mathbf{t}) \\
& -\varepsilon \ln d_{\bullet} \\
& -\varepsilon \ln \left\{1+d_{\bullet}^{-1} e^{-\beta_{3} t-\beta_{4} \mathrm{X}(\mathbf{t})}\left[\delta-k_{I} \tilde{w}(t)-\left(1-k_{I}\right) \tilde{p}_{m}(t)-\beta_{6}\right]\right\} \\
& +\ln \left\{\varepsilon\left(1-k_{I}\right)\left[\tilde{w}(t)-\tilde{p}_{m}(t)\right]-\varepsilon\left(\beta_{3}+\beta_{6}\right)-\varepsilon \beta_{4} \partial \mathrm{X}(\mathbf{t}) / \partial \mathbf{t}\right. \\
& \left.+d_{\bullet} e^{\beta_{3} t+\beta_{4} \mathrm{X}(\mathbf{t})}+\varepsilon O(t)\right\},
\end{aligned}
$$

Where $\beta_{8} \equiv \beta_{5}+\beta_{7}$ and

$$
O(t)=\frac{\tilde{d}(t)\left[\delta-k_{I} \tilde{w}(t)-\left(1-k_{l}\right) \tilde{p}_{m}(t)-\beta_{6}\right]}{\left[d(t)+\delta-k_{I} \tilde{w}(t)-\left(1-k_{l}\right) \tilde{p}_{m}(t)-\beta_{6}\right]}+\frac{k_{l}\left[\frac{\ddot{w}(t)}{w(t)}-\tilde{w}(t)^{2}\right]+\left(1-k_{l}\right)\left[\frac{\ddot{p}_{m}(t)}{p_{m}(t)}-\tilde{p}_{m}(t)^{2}\right]}{\left[d(t)+\delta-k_{l} \tilde{w}(t)-\left(1-k_{l}\right) \tilde{p}_{m}(t)-\beta_{6}\right]}
$$

\footnotetext{
${ }^{9}$ Assuming that the efficiency of medical care decreases with age $\beta_{6}>0$ provides an alternative means to achieve the same result.
} 
which we assume to be small (of order $\widetilde{d}(t) \times \delta, \tilde{d}(t) \times \tilde{w}(t)$, etc).

The demand for medical goods/services (equation 26) increases with wages $w(t)$ and the efficiency of medical care (term $\beta_{6}$ ), and decreases with prices $p_{m}(t)$, education $E$, and the health deterioration rate (terms $d_{0}, \beta_{3}$ and $\left.\beta_{4} \mathbf{X}(t)\right) .{ }^{10}$

3.1.2. Corner solution and regime switching-The corner solution describes the health trajectory in scenario B and in scenario A before age $t_{1}$ (see Figure 1). We have (using equations 18 and 23)

$$
\ln H(t)=\ln H(0)-d_{\bullet} \int_{0}^{t} e^{\beta_{3} s+\beta_{4} \mathrm{X}(\mathrm{s})} d s
$$

and

$$
m(t)=0 .
$$

The time $t_{1}$ when health has deteriorated to the "threshold" level in scenario A (see Figure 1) follows from equating (24) with (28). The model thus implies a switch of regimes at time $t_{1}$. Before $t_{1}$ the evolution of health is given by equation (28), whereas after $t_{1}$ it is given by (24). Empirically, this would generate a switching regression model with endogenous switching. Once health hits the "optimal" path, the process governing health switches from (28) to (24). Similarly, before $t_{1}$ the demand for medical goods/services is given by equation (29), whereas after $t_{1}$ it is given by (25) or, alternatively, by (26).

\subsection{Pure consumption model}

In the following we follow Wagstaff (1986). We impose $\partial Y(t) / \partial H(t)=0$. To convert (13) into estimable equations we have to specify a functional form for the utility function.

We specify the following constant relative risk aversion (CRRA) utility function:

$$
U[C(t), H(t)]=\frac{1}{1-\rho}\left[C(t)^{\zeta} H(t)^{1-\zeta}\right]^{1-\rho},
$$

where $\zeta(0 \leq \zeta \leq 1)$ is the relative "share" of consumption versus health and $\rho(\rho>0)$ the coefficient of relative risk aversion.

The functional form for the utility function can account for the observation that the marginal utility of consumption declines as health deteriorates (e.g., Finkelstein, Luttmer and Notowidigdo, 2008). The authors find that a one-standard deviation increase in the number of chronic diseases is associated with an 11 percent decline in the marginal utility of consumption relative to this marginal utility when the individual has no chronic diseases (the 95 percent confidence interval ranges between 2 percent and 17 percent). This would rule out the strongly separable functional form for the utility function employed by Wagstaff (1986), where the marginal utility of consumption is independent of health. While we follow Wagstaff (1986) in most of the derivations we do not adopt his utility specification.

${ }^{10}$ For $0<\varepsilon<1$. 


\subsubsection{Health threshold}

Structural-form equations: The structural equation for the health "threshold" (Grossman's solution for "optimal" health; the health trajectory in scenario $\mathrm{C}$ and in scenario A after age $t_{1}$, see Figure 1) is as follows

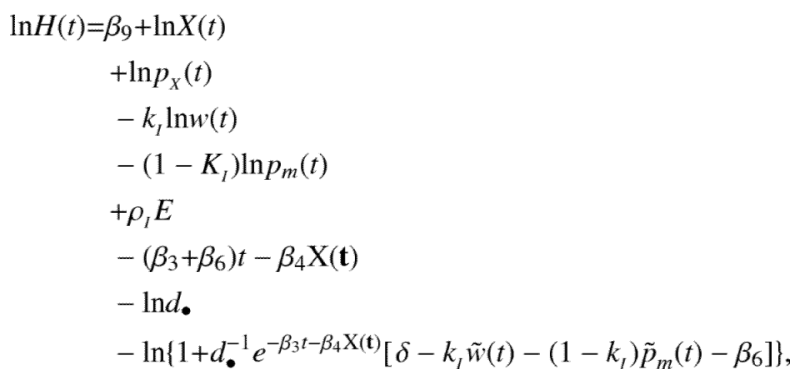

where $\beta_{9} \equiv \ln \mu_{I}(0)-\ln \left(1-k_{C}\right)+\ln \left[k_{I}^{k_{I}}\left(1-k_{I}\right)^{\left(1-k_{I}\right)}\right]+\ln [(1-\zeta) / \zeta]$. The health threshold thus increases with consumption goods $X(t)$, prices for consumption goods $p_{X}(t)$, and education $E$ and decreases with wages $w(t)$, prices of medical goods/services $p_{m}(t)$, and the health deterioration rate (terms $d_{\bullet}, \beta_{3}$ and $\beta_{4} \mathbf{X}(t)$ ). The last term is generally assumed to be small and can be estimated in our formulation.

The structural-form equation for medical goods/services is the same as for the pure investment model (equation 25).

Reduced-form equations: Note that the health threshold (equation 31 ) is expressed directly as a function of consumption goods $X(t)$. This relation is different from the one found by Wagstaff (1986; his equation 12), which is the result of our choice for the functional form of the utility function (equation 30). Wagstaff (1986) finds that health $H(t)$ is a function of the shadow price of wealth $q_{A}(0)$. We can obtain a similar reduced-form expression to the one found by Wagstaff (1986) by using the first-order condition (11) to obtain an expression for consumption good $X(t)$ - assuming that, similar to health investment (see equation 21), consumption $C(t)$ is produced by combining time $\tau_{c}$ and consumption goods $X(t)$ according to a Cobb-Douglass constant returns to scale production function

$$
C(t)=\mu_{C}(t) X(t)^{1-k_{C}} \tau_{C}(t)^{k} c e^{\rho_{C} E},
$$

where $\mu_{C}(t)$ is an efficiency factor, $1-k_{C}$ is the elasticity of consumption $C(t)$ with respect to consumption goods $X(t), k_{C}$ is the elasticity of consumption $C(t)$ with respect to time input $\tau_{C}(t)$, and $\rho_{C}$ determines the extent to which education $E$ improves the efficiency of consumption $C(t)$ - and inserting the expression for $X(t)$ into equation (31). We then find: 


$$
\begin{aligned}
\ln H(t)= & \beta_{10}-\chi(1 / \rho \chi-1)\left(1-k_{C}\right) \ln p_{X}(t) \\
& -\chi\left(1-k_{I}\right) \ln p_{m}(t) \\
& -\chi\left[k_{I}+(1 / \rho \chi-1) k_{C}\right] \ln w(t) \\
& +\chi\left[\rho_{l}+(1 / \rho \chi-1) \rho_{C}\right] E \\
& -\chi\left[\left(\beta_{3}+\beta_{6}\right)+(1 / \rho \chi-1) \beta_{11}+(\beta-\delta) / \rho \chi\right] t \\
& -\chi \beta_{4} \mathrm{X}(\mathbf{t}) \\
& -\chi \ln d_{\bullet} \\
& +\ln q_{A}(0)^{-1 / \rho} \\
& -\chi \ln \left\{1+d_{\bullet}^{-1} e^{-\beta_{3} t-\beta_{4} X(\mathbf{t})}\left[\delta-k_{l} \tilde{w}(t)-\left(1-k_{l}\right) \tilde{p}_{m}(t)-\beta_{6}\right]\right\}
\end{aligned}
$$

where

$$
\beta_{10} \equiv \chi \ln \mu_{l}(0)+\chi(1 / \rho \chi-1) \ln \mu_{C}(0)+\chi \ln \left[k_{I}^{k_{I}}\left(1-k_{l}\right)^{\left(1-k_{l}\right)}\right]+\chi(1 / \rho \chi-1) \ln \left[k_{C}^{k_{C}}\left(1-k_{C}\right)^{\left(1-k_{C}\right)}\right]+\chi \ln [(1-\zeta) / \zeta]+\ln \zeta^{1 / \rho},
$$

and

$$
\chi \equiv \frac{1+\rho \zeta-\zeta}{\rho}
$$

and we allow the efficiency of consumption to depend on age $\mu_{C}(t)=\mu_{C}(0) e^{-\beta_{11} t}$.

An expression for the shadow price of wealth $q_{A}(0)$ in equation (33) can be obtained by using the life-time budget constraint (equation 5), substituting the solutions for consumption, health, and medical care and solving for $q_{A}(0)$ (see, for example, Galama et al. 2009). The shadow price of wealth $q_{A}(0)$ is found to be a complicated function of wealth (assets, lifetime earnings), wages $w(t)$, prices $p_{m}(t), p_{X}(t)$, education $E$ and the health deterioration rate (terms $d_{\bullet}, \beta_{3}$ and $\beta_{4} \mathbf{X}(t)$ ). Wagstaff (1986) provides a simple approximation for the shadow price of wealth $q_{A}(0)$ (his equations 15 and 16) which may be easier to use in empirical testing of the model.

Assuming that both medical goods / services $m(t)$ and time input $\tau_{I}(t)$ increase medical care suggests $0 \leq k_{I} \leq 1$, and if education $E$ increases the efficiency of medical care then $p_{I}>0$ (see equation 21). Similarly we have $0 \leq k_{C} \leq 1$ and $p_{C}>0$ (see equation 55). Finkelstein, Luttmer and Notowidigdo (2008) provide evidence that the marginal utility of consumption declines as health deteriorates. Assuming further diminishing marginal benefits of health $\partial^{2} U(t) / \partial^{2} H(t)<0$ we find $1<\chi<1+1 / \rho$ (and hence $0<\rho<1$ and $1 / \rho \chi>1$ ).

For these parameter values we find that the health threshold (equation 33) increases with education $E$, wealth $q_{A}(0)^{-1 / \rho}$, and decreases with the price of consumption goods $p_{X}(t)$, the price of medical care $p_{m}(t)$, wages $w(t)$, and the health deterioration rate (terms $d_{\bullet}, \beta_{3}$ and $\left.\beta_{4} \mathbf{X}(t)\right)$. The health threshold could increase or decrease with age depending on the sign of $\chi\left(\beta_{3}+\beta_{6}\right)+\chi(1 / \rho \chi-1) \beta_{11}+[(\beta-\delta) / \rho]$ and on the evolution of wages $w(t)$ with years of experience (e.g., Mincer, 1974).

Combining equation (25) with (33) we find: 


$$
\begin{aligned}
\ln m(t)= & \beta_{12} \\
& -\chi(1 / \rho \chi-1)\left(1-k_{C}\right) \ln p_{X}(t) \\
& -\left[k_{I}+\chi\left(1-k_{l}\right)\right] \ln p_{m}(t) \\
& -\chi\left[(1-1 / \chi) k_{I}+(1 / \rho \chi-1) k_{C}\right] \ln w(t) \\
& +\chi\left[(1-1 / \chi) \rho_{I}+(1 / \rho \chi-1) \rho_{C}\right] E \\
& -\chi\left[(1-1 / \chi)\left(\beta_{3}+\beta_{6}\right)+(1 / \rho \chi-1) \beta_{11}+(\beta-\delta) / \rho \chi\right] t \\
& -(\chi-1) \beta_{4} \mathrm{X}(\mathbf{t}) \\
& -(\chi-1) \ln d_{\bullet} \\
& +\ln q_{A}(0)^{-1 / \rho} \\
& -\chi \ln \left\{1+d_{\bullet}^{-1} e^{-\beta_{3} t-\beta_{4} X(\mathbf{t})}\left[\delta-k_{,} \tilde{w}(t)-\left(1-k_{l}\right) \tilde{p}_{m}(t)-\beta_{6}\right]\right\}
\end{aligned}
$$

where $\beta_{12} \equiv \beta_{7}+\beta_{10}$. The demand for medical goods/services (equation 35) increases with education $E$, wealth $q_{A}(0)^{-1 / \rho}$, and decreases with the price of consumption goods $p_{X}(t)$, the price of medical goods/services $p_{m}(t)$, wages $w(t)$, and the health deterioration rate (terms $d_{0}$, $\beta_{3}$ and $\left.\beta_{4} \mathbf{X}(t)\right)$. The health threshold could increase or decrease with age depending on the sign of $\chi(1-1 / \chi)\left(\beta_{3}+\beta_{6}\right)+\chi(1 / \rho \chi-1) \beta_{11}+[(\beta-\delta) / \rho]$ and on the evolution of wages $w(t)$ with years of experience (e.g., Mincer, 1974).

3.2.2. Corner solution and regime switching-The corner solution (the health trajectory in scenario B and in scenario A before age $t_{1}$, see Figure 1) is provided by (28) and (29). The time $t_{1}$ when health has deteriorated to the "threshold" follows from equating (31) or (33) with (28). Similar to the previous discussion for the pure investment model, the model thus implies a switch of regimes at time $t_{1}$. Before $t_{1}$ the evolution of health is given by equation (28), whereas after $t_{1}$ it is given by (31) or by (33). Similarly, before $t_{1}$ medical care is given by equation (29), whereas after $t_{1}$ it is given by (25) or alternatively (35).

\section{Model Predictions}

We assume that each of the scenarios A, B and C occur in reality (see Figure 1). In other words, that there exist healthy individuals who consume medical care during some part of their life (scenario A; initial health above the initial health threshold and the threshold reached during life), very healthy individuals who never consume medical care (scenario B; initial health well above the initial health threshold and the threshold never reached), and unhealthy individuals who consume medical care their entire life (scenario $\mathrm{C}$; initial health at the health threshold). We do not a-priori know the distribution of healthy, very healthy and unhealthy individuals in the population but if a statistically significant share of individuals have initial health endowments $H(0)$ above the initial health threshold $H_{*}(0)$ (scenarios A and B) then empirical tests should be able to distinguish between the interpretation of the Grossman model advocated here (represented by the joint occurrences of scenarios A, B and C) and the interpretation adopted in the literature (represented by scenario C only).

\subsection{Similarities}

The predictions for the demand for health and for medical care for unhealthy individuals (those individuals whose health is at the threshold) in our generalized solution of the Grossman model are, with the exception of some minor differences in formulation, the same as for the original solution of the Grossman model. This can be seen as follows. If at any time the proportion of unhealthy individuals (those whose health is at the health threshold and who behave according to the traditional Grossman solution) is significant this could produce the observed relationships, with the exception of the relation between health and 
medical care. The reason that the relationship between health and medical care is different stems from the significantly different behavior between healthy and unhealthy individuals. The healthy do not consume medical care while the unhealthy do. If both healthy and unhealthy individuals are included in a sample this would produce the observed strong negative relationship between measures of health and measures of medical care. At the same time, if we can restrict the sample to the unhealthy, we should observe the positive relationship between health and medical care as predicted by Grossman.

We summarize our predictions in Table 2. The table is self explanatory, but a few points are worth making. The relation with age $t$ is ambiguous as wages $w(t)$ increase with working experience (e.g., Mincer, 1974) potentially off-setting the "aging" variables $\beta_{3}, \beta_{6}, \beta-\delta$. The effect of wages $w(t)$ is unclear, with a positive effect on health in the pure investment (PI) and a negative effect on health in the pure consumption (PC) model.

\subsection{Differences}

In addition to the above predictions of our generalized solution of the Grossman model that are the same as in the traditional solution of the model, there are a number of distinctly different predictions. Those are presented and discussed in detail in Table 3. We denote the predictions of our interpretation of the Grossman model by Health threshold, the more generally held interpretation by "Optimal" stock and the empirical observations from the literature by Empirical literature. Briefly, the predictions are: 1) medical care and health are negatively correlated if measured across healthy and unhealthy individuals, 2) healthy people do not consume medical care, 3) effective health deterioration slows when individuals reach the health threshold, 4) effective health deterioration and medical care are negatively correlated, 5) medical care increases discontinuously when individuals become unhealthy, 6) blue collar workers let their health deteriorate faster and to lower levels and 7) the relationship between education and health is expected to be positive and differs for healthy and unhealthy individuals.

\section{Discussion}

We have contrasted the predictions of the generalized solution of the Grossman model advocated here with the empirical literature. Our generalized solution replicates the predictions of the traditional Grossman model (which have largely been verified in the empirical literature) with the exception of the problematic prediction that health and medical care should be positively correlated (which has been rejected in the empirical literature). As with the traditional solution of the Grossman model (a special case of our generalized solution) we broadly expect health to decrease with the cost of medical goods/services and with environmental factors that are detrimental to health (e.g., working conditions) and to increase with education. The effect of income is unclear as different sub models predict a different relation with health. With regard to the demand for medical care, we expect medical care to decrease with the cost of medical goods/services $p_{m}(t)$ and with education, and to increase with wages and with environmental factors that are detrimental to health.

In addition, our generalized solution of the Grossman model produces a number of predictions that are different from the traditional solution of the Grossman model. First, it replicates the observed negative relation between health and medical care as in our generalized solution of the Grossman model healthy individuals (whose health is above the health threshold) do not consume medical care while the unhealthy (at the threshold) do. Second, we find that individuals do not consume medical care at all times as healthy people do not consume medical care. Basically our generalized solution of the Grossman model predicts the intuitively natural behavior that healthy individuals do not go to the doctor or stay in hospital while the unhealthy do (except for preventive care or as a result of a sudden 
health shock, both phenomena are currently not part of the Grossman model). Third, we find that effective health deterioration slows as individuals reach the health threshold and begin to consume medical care. Fourth, our generalized solution of the Grossman model predicts that the effective health deterioration rate $\dot{H}(t)$ (the net effect of "aging" and medical care) will be smaller for individuals who consume more medical care. Fifth, we predict that the consumption of medical care increases discontinuously as healthy individuals begin to consume medical care once their health reaches the health threshold. Sixth, our generalized solution of the Grossman model can account for the observation that blue collar workers tend to have faster rates of effective health deterioration $\dot{H}(t)$ than white collar workers (e.g., Case and Deaton, 2005). Lastly, because the model distinguishes between healthy and unhealthy individuals who behave differently, the model allows for a number of tests that are not possible in the traditional interpretation of the Grossman model. For example, Muurinen (1982) has argued that education improves health through lowering the natural health deterioration rate $d(t)$ (aging) and not just (or perhaps not at all) through improving the efficiency of an individual's consumption of medical care (Grossman, 1972a, 1972b). Since the first pathway (lowering the deterioration rate) operates only for healthy individuals and both pathways operate for unhealthy individuals it should in theory be possible to establish empirically the relative importance of both pathways. Also, while the natural deterioration rate $d(t)$ is not directly observable in the traditional interpretation of the Grossman model, it is directly observable in our interpretation as individuals who are healthy let their health deteriorate at exactly this rate (assuming good empirical measures of health status are available).

A review of the empirical literature suggests that our generalized solution of the Grossman model can account for a greater number of observations than can the traditional solution. Ultimately though, the model needs to be verified in direct empirical testing. To this end we have provided detailed structural- and reduced-form equations for the pure consumption and pure investment models for both the healthy and unhealthy phases of life. Empirically, the proposed model is a switching regression model with endogenous switching. Once health hits the health threshold, the process governing health and medical care switches. The switch from the healthy stage to the unhealthy stage occurs when health in the two regimes (viewed as potential outcomes) is equal. Before the switch, health in the healthy regime is better than the optimal health stock, whereas continuation without medical expenditures after the switch point would result in worse health than the optimal level. Hence, actual health is the maximum of the two and the effective regime at any age is the regime that delivers this maximum health. This resembles the Roy (1951) model for occupational choice in which the occupation that maximizes earnings is chosen. Estimation of the Roy model is not always trivial, but our model has enough structure to identify the parameters. In particular, one can correct for individual heterogeneity and observe individuals switching from one regime to another which, combined with the model structure, allows inference of the counterfactuals (what health would be in the regime that is not the actual regime). Estimation of the model then will be a generalization of a switching regression method (see for instance Heckman and Taber, 2008).

\section{Appendix: derivations}

\subsection{First-order conditions}

Associated with the Lagrangian (equation 10) we have the following conditions: 


$$
\begin{aligned}
& \dot{q}_{A}(t)=-\partial \mathfrak{I}(t) / \partial A(t) \Rightarrow \\
& \dot{q}_{A}(t)=-\partial q_{A}(t) \Longleftrightarrow \\
& q_{A}(t)=q_{A}(0) e^{-\delta t}, \\
& \dot{q}_{H}(t)=\quad-\partial \mathfrak{I}(t) / \partial H(t) \Rightarrow \\
& \dot{q}_{H}(t)=q_{H}(t) d(t)-\frac{\partial U(t)}{\partial s(t)} \frac{\partial s(t)}{\partial H(t)} e^{-\beta t}-q_{A}(0) e^{-\delta t} \frac{\partial Y[H(t)]}{\partial s(t)} \frac{\partial s(t)}{\partial H(t)}, \\
& \begin{array}{rlc}
\partial \Im(t) / \partial X(t) & = & 0 \Rightarrow \\
\partial U(t) / \partial C(t) & = & q_{A}(0)\left(\frac{p_{X}(t)}{\partial C(t) / \partial X(t)}\right) e^{(\beta-\delta) t} \\
& \equiv & q_{A}(0) \pi_{C} e^{(\beta-\delta) t},
\end{array} \\
& \partial \Im(t) / \partial \tau_{C}(t)=\quad 0 \Rightarrow \\
& \partial U(t) / \partial C(t)=q_{A}(0)\left(\frac{w(t)}{\partial C(t) / \partial \tau_{C}(t)}\right) e^{(\beta-\delta) t} \\
& \equiv q_{A}(0) \pi_{C} e^{(\beta-\delta) t} \text {, } \\
& \partial \Im(t) / \partial m(t)=\quad 0 \Rightarrow \\
& q_{H}(t)+q_{I}(t)=q_{A}(0)\left(\frac{p_{m}(t)}{\partial I(t) / \partial m(t)}\right) e^{-\delta t} \\
& \equiv q_{A}(0) \pi_{t} e^{-\delta t}, \\
& \partial \Im(t) / \partial \tau_{l}(t)=\quad 0 \Rightarrow \\
& q_{H}(t)+q_{I}(t)=q_{A}(0)\left(\frac{w(t)}{\partial I(t) / \partial \tau_{I}(t)}\right) e^{-\delta t} \\
& \equiv q_{A}(0) \pi_{t} e^{-\delta t} \text {. }
\end{aligned}
$$

Equation (38) provides the first-order condition for maximization of (1) with respect to consumption, subject to the conditions (2) and (3). Using (40) to obtain an expression for $\dot{q}_{H}(t)$ and substituting the results for $q_{H}(t)$ and $\dot{q}_{H}(t)$ in (37) we find the first-order condition for maximization of (1) with respect to health, subject to the conditions (2) and (3). The resulting first-order conditions are provided by equations (11) and (13) in section 2.

\subsection{Structural and reduced form: pure investment model}

We begin with the first-order condition for optimal health (13). We have (using equations 19 through 22)

$$
\begin{gathered}
\pi_{l}(t)=\frac{\partial Y(t)}{\partial s(t)} \frac{\partial s(t)}{\partial H(t)}\left[d(t)+\delta-\tilde{\pi}_{l}(t)\right]^{-1} \\
=\beta_{1} \beta_{2} w(t) H(t)^{-\left(\beta_{2}+1\right)}\left[d(t)+\delta-\tilde{\pi}_{l}(t)\right]^{-1}
\end{gathered}
$$




$$
=\frac{p_{m}(t)}{\partial I(t) / \partial m(t)}=\frac{e^{-\rho_{l} E}}{\mu_{I}(t) k_{I}^{k_{I}}\left(1-k_{I}\right)^{\left(1-k_{l}\right)}} w(t)^{k_{l}} p_{m}(t)^{\left(1-k_{l}\right)} .
$$

This leads to the structural form equation (24).

Now consider the equations for medical health investment (equations 2 and 21) and using (22),

$$
\begin{gathered}
\ln I(t)=\rho_{l} E+\left(1-k_{l}\right) \ln m(t)+k_{I} \ln \tau_{I}(t)+\ln \mu_{I}(t) \\
=\rho_{l} E+\ln m(t)+k_{l} \ln p_{m}(t)-k_{I} \ln w(t)+\ln \mu_{I}(t)+k_{l} \ln \left[k_{l} /\left(1-k_{l}\right)\right] \\
=\ln [\dot{H}(t)+d(t) H(t)] \\
=\ln d(t)+\ln H(t)+\ln [1+\tilde{H}(t) / d(t)] .
\end{gathered}
$$

This leads to the structural form equation (25).

Using (24) and (25) we find

$$
\begin{aligned}
\ln m(t)= & \beta_{8}+\left[k_{l}+\varepsilon\left(1-k_{l}\right)\right] \ln w(t)-\left[k_{l}+\varepsilon\left(1-k_{l}\right)\right] \ln p_{m}(t) \\
& -(1-\varepsilon) \rho_{l} E \\
& +(1-\varepsilon) \ln d_{\bullet} \\
& +(1-\varepsilon)\left(\beta_{3}+\beta_{6}\right) t \\
& +(1-\varepsilon) \beta_{4} \mathrm{X}(\mathbf{t}) \\
& -\varepsilon \ln \left\{1+d_{\bullet}^{-1} e^{-\beta_{3} t-\beta_{4} X(\mathbf{t})}\left[\delta-k_{I} \tilde{w}(t)-\left(1-k_{I}\right) \tilde{p}_{m}(t)-\beta_{6}\right]\right\} \\
& +\ln [1+\tilde{H}(t) / d(t)],
\end{aligned}
$$

where $\beta_{8} \equiv \beta_{5}+\beta_{7}$.

Combining equations (46) and (47) we find:

$$
\dot{H}(t)+d(t) H(t)=\mu_{l}(t)\left[k_{l} /\left(1-k_{l}\right)\right]^{k_{l}} m(t) p_{m}(t)^{k_{l}} w(t)^{-k_{l}} e^{\rho_{l} E},
$$

the solution of which is

$$
H(t)=e^{\rho_{I}} E_{[}\left[k_{I} /\left(1-k_{l}\right)\right]^{k_{I}} \int_{0}^{t} \mu_{I}(x) m(x) p_{m}(x)^{k_{l}} w(x)^{-k_{l}} e^{-\int_{x}^{t} d(s) d s} d x .
$$

We then have 


$$
1+\tilde{H}(t) / d(t)=\frac{\mu_{I}(t) m(t) p_{m}(t)^{k_{l}} w(t)^{-k_{l}}}{d(t) \int_{o}^{t} \mu_{I}(x) m(x) p_{m}(x)^{k_{l}} w(x)^{-k_{l}} e^{-\int_{x}^{t} d(s) d s} d x} .
$$

Substituting equation (52) into equation (49) and differentiating the result with respect to time $t$ we find the reduced form expression (26).

While the literature largely focuses on the relations for health $H(t)$ and medical goods/ services $m(t)$ the model does allow for the derivation of relations for consumption goods $X(t)$ and assets $A(t)$. In the pure investment model we have $\partial U(t) / \partial H(t)=0$, i.e. utility $U(t)$ is independent of health $H(t)$. We assume a simple functional form for the utility function:

$$
U[C(t)]=\frac{C(t)^{1-\rho}}{1-\rho} .
$$

The first-order condition (equation 11) then leads to:

$$
C(t)^{-\rho}=q_{A}(0) \pi_{C}(t) e^{(\beta-\delta) t} .
$$

Grossman (1972a, 1972b, 2000) assumes that medical health investment is produced by combining time and medical goods/service according to a Cobb-Douglass constant returns to scale production function (see equation 21). A similar assumption can be made that consumption is produced by combining time $\tau_{c}$ and consumption goods $X(t)$ as follows:

$$
C(t)=\mu_{C}(t) X(t)^{1-k_{C}} \tau_{C}(t)^{k_{C}} e^{\rho_{C} E},
$$

where $\mu_{C}(t)$ is an efficiency factor, $1-k_{C}$ is the elasticity of consumption $C(t)$ with respect to consumption goods $X(t), k_{C}$ is the elasticity of consumption $C(t)$ with respect to time input $\tau_{C}(t)$, and $\rho_{C}$ determines the extent to which education $E$ improves the efficiency of consumption $C(t)$.

Further the ratio of the marginal product of medical care with respect to medical goods/ services $\partial I(t) / \partial m(t)$ and the marginal product of medical care with respect to own-time investment $\partial I(t) / \partial \tau_{I}(t)$ equals the ratio of the price of medical goods/services $p_{m}(t)$ to the wage rate $w(t)$ (representing the opportunity cost of time; see equation 22). Similarly, the ratio of the marginal product of consumption with respect to consumption goods $\partial C(t) / \partial X(t)$ and the marginal product of consumption with respect to time inputs $\partial C(t) / \partial \tau_{C}(t)$ equals the ratio of the price of consumption good $p_{X}(t)$ to the wage rate $w(t)$ (see equation 12 ). We then have

$$
\pi_{I}(t)=\frac{p_{m}(t)}{\partial I(t) / \partial m(t)}=\frac{p_{m}(t)^{1-k_{l}} w(t)^{k_{l}} e^{-\rho_{I} E}}{\mu_{I}(t) k_{l}^{k_{I}}\left(1-k_{l}\right)^{\left(1-k_{l}\right)}}
$$




$$
\pi_{C}(t)=\frac{p_{X}(t)}{\partial C(t) / \partial X(t)}=\frac{p_{X}(t)^{1-k_{C}} w(t)^{k_{C}} e^{-\rho_{C} E}}{\mu_{C}(t) k_{C}^{k_{C}}\left(1-k_{C}\right)^{\left(1-k_{C}\right)}} .
$$

Assuming the Cobb-Douglass constant returns to scale production function for medical health investment (equation 21) and for consumption (equation 55) we obtain the following expressions for consumption goods $X(t)$ and medical goods/services $m(t)$

$$
\begin{gathered}
X(t)=\left(1-k_{C}\right) \frac{\pi_{C}(t)}{p_{X}(t)} C(t), \\
m(t)=\left(1-k_{I}\right) \frac{\pi_{I}(t)}{p_{m}(t)}[\dot{H}(t)-d(t) H(t)] .
\end{gathered}
$$

Using equations $(54,57$, and 58) we find

$\ln X(t)=\beta_{13}-\left[k_{C}+\left(1-k_{C}\right) / \rho\right] \ln p_{X}(t)+k_{C}[(\rho-1) / \rho] \ln w(t)-\rho_{C}[(\rho-1) / \rho] E-[(\beta-\delta) / \rho] t+\ln q_{A}(0)^{-1 / \rho}$,

Where $\beta_{13} \equiv \ln \left(1-k_{C}\right)-[(\rho-1) / \rho] \ln \left[k_{C}^{k_{C}}\left(1-k_{C}\right)^{\left(1-k_{C}\right)}\right]-[(\rho-1) / \rho] \ln \mu_{C}(t)$.

It is straightforward though tedious to derive an expression for the shadow price of life-time wealth $q_{A}(0)$, using the life-time budget constraint (5), the expression for sick time $s[H(t)]$ (equation 19), income $Y[H(t)]$ (equation 9), consumption good $X(t)$ (the above equation), health $H(t)$ (equation 24), and medical goods/services $m(t)$ (equation 25). $q_{A}(0)$ is then found to be a complicated function of life-time wealth (assets, life-time income), wages $w(t)$, prices $p_{m}(t), p_{X}(t)$, education $E$ and the health deterioration rate (terms $d_{\bullet}, \beta_{3}$ and $\beta_{4} \mathbf{X}(t)$ ). The expression itself is not very insightful and is hence not reproduced here.

\subsection{Structural and reduced form: pure consumption model}

Using the utility specification (30) and the first-order conditions (11) and (13), we find

$$
\begin{array}{ccc} 
& \frac{\partial U[C(t), H(t)]}{\partial C(t)}=\zeta C(t)^{\zeta-\rho \zeta-1} H(t)^{1-\zeta-\rho+\rho \zeta} \\
& = & q_{A}(0) \pi_{C}(t) e^{(\beta-\delta) t} \\
\frac{\partial U[C(t), H(t)]}{\partial H(t)}= & \\
= & q_{A}(0)\left[\pi_{H}(t)-\varphi_{H}(t)\right] e^{(\beta-\delta) t}+\left[\dot{q}_{I}(t)-q_{I}(t) d(t)\right] e^{\beta t} \\
= & \pi_{C}(t)^{-1}\left[\pi_{H}(t)-\varphi_{H}(t)\right] \frac{\partial U[C(t), H(t)]}{\partial C(t)}+\left[\dot{q}_{I}(t)-q_{I}(t) d(t)\right] e^{\beta t}
\end{array}
$$

The solution for the health threshold (Grossman's solution for "optimal" health) follows from combining equation (61) with (62), assuming $\varphi_{H}(t)=0$ (pure consumption) and using $q_{I}(t)=\dot{q}_{I}(t)=0$. We then find: 
$\ln H(t)=\ln C(t)+\ln \left(\frac{1-\zeta}{\zeta}\right)+\ln \pi_{C}-\ln \pi_{I}-\ln d(t)-\ln \left[1+\delta / d(t)-\tilde{\pi}_{I}(t) / d(t)\right]$

Combining equations $(23,56,57,58$ and the above expression) leads to the structural form equation (31). Further, combining equations (58, 61, 62 and 63) we find:

$$
H(t)=q_{A}(0)^{-1 / \rho} \zeta^{1 / \rho}\left(\frac{1-\zeta}{\zeta}\right)^{\chi} \pi_{C}(t)^{-\chi(1 / \rho \chi-1)} \pi_{I}(t)^{-\chi} d(t)^{-\chi} \times\left[1+\delta / d(t)-\tilde{\pi}_{I}(t) / d(t)\right]^{-\chi}
$$

which leads to the structural form equation (33).

As in the pure investment model one can find and expression for the shadow price of lifetime wealth $q_{A}(0)$ for the pure consumption model, using the life-time budget constraint (5), the expressions for income $Y[H(t)]$ (equation 9), medical goods/services $m(t)$ (equation 25), health $H(t)$ (equation 33), and consumption good $X(t)$ (equation 58). As in the pure investment model the expression is found to be a complicated function of life-time wealth (assets, life-time income), wages $w(t)$, prices $p_{m}(t), p_{X}(t)$, education $E$ and the health deterioration rate (terms $d_{\bullet}, \beta_{3}$ and $\beta_{4} \mathbf{X}(t)$ ).

\section{References}

Case, A.; Deaton, A. Broken Down by Work and Sex: How our Health Declines. In: Wise, DA., editor. Analyses in the Economics of Aging. The University of Chicago Press; Chicago: 2005. p. 185-212.

Cochrane AL, St Leger AS, Moore F. Health service 'input' and mortality 'output' in developed countries. J Epid Communit Hlth. 1978; 32:200-205.

Cropper ML. Health, Investment in Health, and Occupational Choice. The Journal of Political Economy. 1977; 85(6):1273-1294.

Cropper, ML. Measuring the Benefits from Reduced Morbidity. The American Economic Review; Papers and Proceedings of the Ninety-Third Annual Meeting of the American Economic Association; 1981. p. 235-240.

Ehrlich I, Chuma H. A Model of the Demand for Longevity and the Value of Life Extension. The Journal of Political Economy. 1990; 98(4):761-782. [PubMed: 11617449]

Erbsland, M.; Ried, W.; Ulrich, V. Econometric Analysis of Health Data. John Wiley \& Sons, Ltd; 2002. Health, Health Care, and the Environment: Econometric Evidence from German Micro Data; p. 25-36.

Finkelstein, A.; Luttmer, EFP.; Notowidigdo, MJ. The Effect of Health on the Marginal Utility of Consumption NBER Working Paper 14089. 2008. What Good Is Wealth Without Health?.

Galama, TJ.; Kapteyn, A.; Fonseca, F.; Michaud, PC. RAND Working Paper WR-658. 2009. Grossman's Health Threshold and Retirement.

Heckman, JJ.; Taber, C. Roy model. In: Durlauf, SN.; Blume, LE., editors. The New Palgrave Dictionary of Economics. 2nd. Palgrave MacMillan; 2008.

Goldman DP, Smith JP. Can Patient Self-Management Help Explain the SES Health Gradient? PNAS. 2002; 99:10929-10934. [PubMed: 12140364]

Grossman, M. The Demand for Health-A theoretical and Empirical Investigation. New York: National Bureau of Economic Research; 1972a.

Grossman M. On the Concept of Health Capital and the Demand for Health. The Journal of Political Economy. 1972b; 80(2):223-255.

Grossman, M. The Human Capital Model. In: Culyer, AJ.; Newhouse, JP., editors. Handbook of Health Economics. Vol. 1. Elsevier Science; Amsterdam: 2000. p. 347-408. 
Leu, RE.; Doppman, RJ. Gesundheitszustandsmessung und Nachfrage nach Gesundheitsleistungen. In: Wille, E., editor. Informations- und Planungsprobleme in Offentlichen Aufgabenbereichen. Frankfurt am Main/Bern/New York: Lang; 1986. p. 1-90.

Leu, RE.; Gerfin, M. Die Nachfrage nach Gesundheit - Ein Empirisher Test des Grossman-Modells (Demand for health - an empirical test of the Grossman model). In: Oberender, P., editor. Steuerungsprobleme im Gesundheitswesen. Baden-Baden: Nomos; 1992. p. 61-78.

Mincer, JA. Schooling, Experience, and Earnings. Columbia University Press; 1974.

Muurinen JM. Demand for health: a generalized Grossman model. Journal of Health Economics. 1982; 1:5-28. [PubMed: 10263949]

Muurinen JM, Le Grand J. The Economic Analysis of Inequalities. Health Soc Sci Med. 1985; 20(10): 1029-1035.

Ried W. Comparative dynamic analysis of the full Grossman model. Journal of Health Economics. 1998; 17:383-425. [PubMed: 10180925]

Roy AD. Some thoughts on the distribution of earnings. Oxford Economic Papers. 1951; 3:135-146.

Seierstad, A.; Sydsaeter, K. Optimal Control Theory With Economic Applications. In: Bliss, CJ.; Intriligator, MD., editors. Advanced Texbooks in Economics. Vol. 24. Elsevier; North Holland: 1987.

Smith JP. Healthy bodies and thick wallets. Journal of Economic Perspectives. 1999; 13(2):145-166.

Smith J. Unraveling the SES-health connection. Aging, Health, and Public Policy: Demographic and Economic Perspectives, a supplement to Population and Development Review. 2004; 30:108-132.

Smith JP. The impact of socioeconomic status on health over the life course. Journal of Human Resources. 2007; 42(4):739-764.

Van Doorslaer EK. Health, knowledge and the demand for medical care. Assen. 1987; 171

Van Doorslaer, EK.; Van Kippersluis, H.; O'Donnell, O.; Van Ourti, T. Socioeconomic Differences in Health over the Life Cycle: Evidence and Explanations. Netspar Panel paper prepared for the Netspar Panel Day 16 October, 2008; Tilburg. 2008.

Van Kippersluis, H.; Van Ourti, T.; O'Donnell, O.; Van Doorslaer, E. Tinbergen Institute discussion paper series 08-009/3. Erasmus University Rotterdam; 2008. Health and income across the life cycle and generations in Europe.

Van Kippersluis, H.; O'Donnell, O.; van Doorslaer, E.; Van Ourti, T. Tinbergen Institute discussion paper series 09-006/3. Erasmus University Rotterdam; 2009. Socioeconomic Differences in Health over the Life Cycle in an Egalitarian Country.

Van de Ven W, van der Gaag J. Health as an unobservable: A MIMIC-model of the demand for health care. Journal of Health Economics. 1982; 1:157-183. [PubMed: 10263954]

Wagstaff A. The demand for health: Some new empirical evidence. Journal of Health Economics. 1986; 5:195-233. [PubMed: 10279033]

Wagstaff A. The demand for health: An empirical reformulation of the Grossman model. Health Economics. 1993; 2:189-198. [PubMed: 8261039]

Wolfe JR. A Model of Declining Health and Retirement. The Journal of Political Economy. 1985; 93(6):1258-1267.

Zweifel, P.; Breyer, F. Health Economics. Oxford University Press; New York: 1997. 


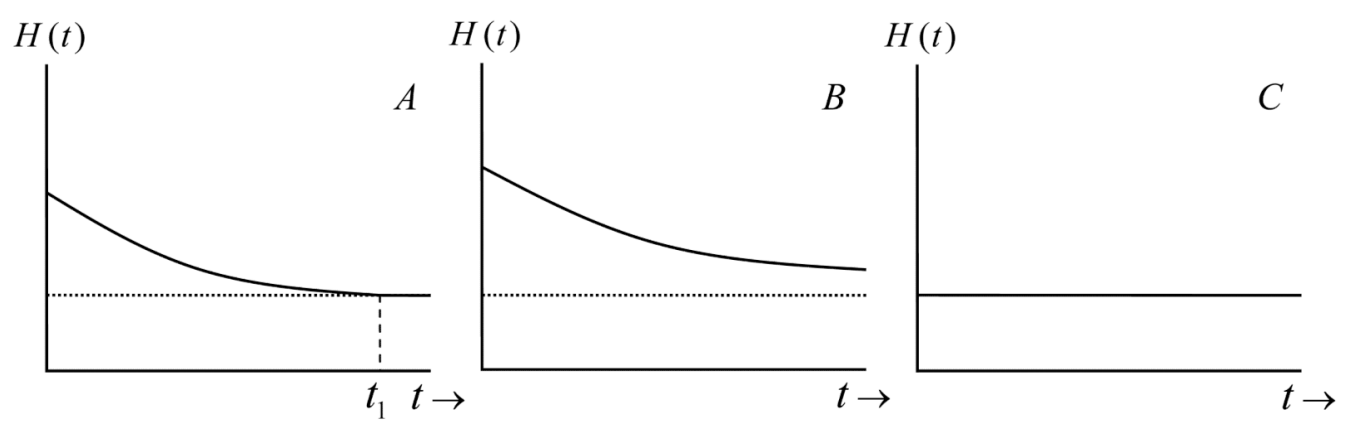

Figure 1.

Three scenarios for the evolution of health. $t_{1}$ in scenario A denotes the age at which health (solid line) has evolved towards the threshold health level (dotted line). 
Table 1

\section{Description of variables and functions}

\begin{tabular}{|c|c|}
\hline Variable / Function & Description \\
\hline$t$ & Age \\
\hline$C(t)$ & Consumption \\
\hline$H(t)$ & Health \\
\hline$I(t)$ & Health investment \\
\hline$d(t)$ & Natural health deterioration rate \\
\hline$\dot{H}(t)$ & Effective health deterioration rate $\dot{H}(t)=\partial H(t) / \partial t$ \\
\hline$A(t)$ & Assets \\
\hline$Y[H(t)]$ & Earnings \\
\hline$X(t), p_{X}(t)$ & Consumption goods/services and their price \\
\hline$m(t), p_{m}(t)$ & Medical goods/services and their price \\
\hline$\tau_{I}(t), \tau_{C}(t)$ & Time inputs into health investment and consumption \\
\hline$\tau_{w}(t)$ & Time spent working \\
\hline$s[H(t)]$ & Sick time \\
\hline$\beta$ & Subjective discount factor \\
\hline$\delta$ & Interest rate \\
\hline E & Consumers stock of knowledge (e.g., education) \\
\hline$w(t)$ & Wage rate \\
\hline$\Omega$ & Total time available in a period \\
\hline$\pi_{H}(t)$ & User cost of health capital \\
\hline$\varphi_{H}(t)$ & Production benefit of health \\
\hline$\pi_{I}(t), \pi_{C}(t)$ & Marginal cost of health investment and of consumption \\
\hline$q_{A}(t), q_{H}(t), q_{I}(t)$ & Lagrange multipliers \\
\hline$q_{A}(0)$ & Shadow price of wealth \\
\hline$\beta_{0}, \beta_{1}, \beta_{2}$ & Parameters of sick time (equation 19) \\
\hline$\mu_{I}(t), \mu_{C}(t)$ & The efficiencies of health investment and of consumption \\
\hline$k_{I}$ & Elasticity of health investment $I(t)$ with respect to time input $\tau_{I}(t)$ \\
\hline $1-k_{I}$ & Elasticity of health investment $I(t)$ with respect to medical goods/services $m(t)$ \\
\hline$k_{C}$ & Elasticity of consumption $C(t)$ with respect to time input $\tau_{C}(t)$ \\
\hline $1-k_{C}$ & Elasticity of consumption $C(t)$ with respect to consumption goods/services $X(t)$ \\
\hline$\rho_{I}, \rho_{C}$ & Coefficients of education $E$ in the health investment and consumption production functions \\
\hline$d_{.}, \beta_{3}, \beta_{4}$ & Parameters of the natural deterioration rate $d(t)$ (equation 23) \\
\hline $\mathbf{X}(t)$ & Vector of environmental variables that affect the deterioration rate \\
\hline$\beta_{5}, \beta_{7}, \beta_{8}, \beta_{9}, \beta_{10}, \beta_{12}$ & Constants in equations (24), (25), (26), (31), (33) and (35) \\
\hline$\varepsilon$ & $\varepsilon \equiv\left(\beta_{2}+1\right)^{-1}$ \\
\hline$\beta_{6}, \beta_{11}$ & Exponential aging rates of medical efficiency $\mu_{I}(t)$ and consumption efficiency $\mu_{C}(t)$ \\
\hline$t_{1}$ & Age at which health reaches the threshold (scenario A in Figure 1) \\
\hline$\zeta$ & Relative "share" of consumption in the utility function (equation 30) \\
\hline
\end{tabular}

J Health Econ. Author manuscript; available in PMC 2012 September 1. 


\begin{tabular}{|l|l|}
\hline Variable / Function & Description \\
\hline$\rho$ & $\begin{array}{l}\text { Coefficient of relative risk aversion } \\
\chi \equiv(1+\rho \zeta-\zeta) / \rho\end{array}$ \\
\hline
\end{tabular}


Table 2

Relationships between the health threshold (Health) and various model variables and between the demand for medical care (Medical care) and various model variables for both the pure investment (PI) and the pure consumption (PC) models (structural form [S] and reduced form [R]). Equation numbers (Eq.) refer to the structural-form equations in section 3 .

\begin{tabular}{|c|c|c|c|c|}
\hline & \multicolumn{3}{|c|}{ Health } & \multirow{3}{*}{$\begin{array}{c}\text { Medical care } \\
\text { PI/PC } \\
\text { Eqs. } 25\end{array}$} \\
\hline & $\mathbf{P I}^{a}$ & $\mathbf{P C}(\mathbf{S})$ & $\mathbf{P C}(\mathbf{R})^{b}$ & \\
\hline & Eq. 24 & Eq. 31 & Eq. 33 & \\
\hline Health $H(t)$ & $\mathrm{n} / \mathrm{a}$ & $\mathrm{n} / \mathrm{a}$ & $\mathrm{n} / \mathrm{a}$ & + \\
\hline Wages $w(t)$ & + & - & - & + \\
\hline Price of medical goods/services $p_{m}(t)$ & - & - & - & - \\
\hline Education $E$ & + & + & + & - \\
\hline Age $t$ & $?$ & $?$ & $?$ & $?$ \\
\hline Unhealthy environment $\mathbf{X}(t), d_{\bullet}, \beta_{3}$ & - & - & - & + \\
\hline Consumption good $X(t)$ & $\mathrm{n} / \mathrm{a}$ & + & $\mathrm{n} / \mathrm{a}$ & $\mathrm{n} / \mathrm{a}$ \\
\hline Price of consumption good $p_{X}(t)$ & $\mathrm{n} / \mathrm{a}$ & + & - & $\mathrm{n} / \mathrm{a}$ \\
\hline Wealth $q_{A}(0)^{-1 / \rho}$ & $\mathrm{n} / \mathrm{a}$ & $\mathrm{n} / \mathrm{a}$ & + & $\mathrm{n} / \mathrm{a}$ \\
\hline Efficiency of medical care $-\beta_{6}$ & + & + & + & - \\
\hline
\end{tabular}


Table 3

Predictions of our interpretation of the Grossman model (Health threshold), contrasted with the more generally held interpretation ("Optimal" stock) and empirical observations from the literature (Empirical literature)

\begin{tabular}{|c|c|c|c|}
\hline Prediction & “Optimal” stock & Health threshold & Empirical literature \\
\hline $\begin{array}{l}\text { 1) Medical care and } \\
\text { health are negatively } \\
\text { correlated if measured } \\
\text { across healthy and } \\
\text { unhealthy individuals. }\end{array}$ & $\begin{array}{l}\text { Medical care and health are } \\
\text { positively correlated (see eq. } \\
25 \text { ). }\end{array}$ & $\begin{array}{l}\text { Healthy individuals do not } \\
\text { consume medical care, while } \\
\text { unhealthy individuals do. } \\
\text { Measured across a sample of } \\
\text { healthy and unhealthy individuals } \\
\text { we expect to observe a negative } \\
\text { correlation between medical care } \\
\text { and health. }\end{array}$ & $\begin{array}{l}\text { A persistent and highly statistically } \\
\text { significant negative relation is found } \\
\text { between measures of health and measures of } \\
\text { medical care in structural-form estimates of } \\
\text { the demand for medical care (see, e.g., } \\
\text { Grossman, 1972a; Wagstaff, 1986, 1993; } \\
\text { Leu and Doppman, 1986; Leu and Gerfin, } \\
\text { 1992; van Doorslaer, 1987; Van de Ven and } \\
\text { van der Gaag, 1982; Erbsland, Ried and } \\
\text { Ulrich, 2002). }\end{array}$ \\
\hline $\begin{array}{l}\text { 2) Healthy people do not } \\
\text { consume medical care. }\end{array}$ & $\begin{array}{l}\text { Individuals consume } \\
\text { medical care at all ages. }\end{array}$ & $\begin{array}{l}\text { Healthy individuals do not } \\
\text { consume medical goods/services, } \\
\text { i.e. we would expect some } \\
\text { fraction of the population at any } \\
\text { given time to not consume } \\
\text { medical goods/services. }\end{array}$ & $\begin{array}{l}\text { Healthy people pay few visits to the doctor } \\
\text { (perhaps only to prevent illness, such as for } \\
\text { a "health check up") and do not require } \\
\text { much medical care (hospital stays, use } \\
\text { medicine, etc). For example, Wagstaff } \\
\text { (1986) observes that } 48 \% \text { of the } 1976 \\
\text { Danish Welfare Survey (DWA) sample he } \\
\text { employed recorded zero general practitioner } \\
\text { visits and } 46.5 \% \text { recorded zero weeks in } \\
\text { hospital }\end{array}$ \\
\hline $\begin{array}{l}\text { 3) Effective health } \\
\text { deterioration slows when } \\
\text { individuals reach the } \\
\text { health threshold. }\end{array}$ & $\begin{array}{l}\text { Health evolves as } \\
\text { Grossman's "optimal" } \\
\text { health stock, i.e. we do not } \\
\text { expect to see discontinuous } \\
\text { changes in the evolution of } \\
\text { health. }\end{array}$ & $\begin{array}{l}\text { Healthy people do not consume } \\
\text { medical goods/services and } \dot{H}(t)= \\
-d(t) H(t) \text { is fast. When, their } \\
\text { health reaches the health } \\
\text { threshold they begin to consume } \\
\text { medical goods/services and } \dot{H}(t)= \\
I(t)-d(t) H(t) \text { is slower. }\end{array}$ & $\begin{array}{l}\text { In most developed countries health } \\
\text { deteriorates gradually from early adulthood } \\
\text { until around age } 50 \text { after which it generally } \\
\text { levels off before accelerating rapidly after } \\
\text { age } 70 \text { (Smith, 2004, 2007; Van Doorslaer et } \\
\text { al. } 2008 \text {; Van Kippersluis et al. 2008, 2009; } \\
\text { Case and Deaton, 2005). This middle-age } \\
\text { plateau (ages 50-70) would be consistent } \\
\text { with a slowing of the decline in health } \\
\text { resulting from increased medical care as the } \\
\text { average individual reaches a health } \\
\text { threshold. After age } 70 \text {, as terminal illnesses } \\
\text { set in, health again declines rapidly. }\end{array}$ \\
\hline $\begin{array}{l}\text { 4) Effective health } \\
\text { deterioration and } \\
\text { medical care are } \\
\text { negatively correlated. }\end{array}$ & $\begin{array}{l}\text { Assuming slow variation in } \\
\text { wages, prices and } \\
\text { environment, we have } \dot{H}(t) \\
\propto-\varepsilon\left(\beta_{3}+\beta_{6}\right) H(t) \text { and } \ln \\
m(t) \propto \ln H(t)+\left(\beta_{3}+\beta_{6}\right)^{t} \\
\text { (equations } 24 \text { and } 25), \\
\text { producing a positive } \\
\text { correlation between } \dot{H}(t) \\
\text { and } m(t) .{ }^{a}\end{array}$ & $\begin{array}{l}\text { Healthy individuals have fast } \\
\text { deterioration } \dot{H}(t)=-d(t) H(t) \text { and } \\
\text { low demand for medical care } I(t) \\
=0 \text { while unhealthy individuals } \\
\text { have slow } \dot{H}(t)=I(t)-d(t) H(t) \\
\text { and high demand for medical care } \\
I(t)>0 \text { ). This would produce a } \\
\text { negative correlation between } \dot{H}(t) \\
\text { and } I(t) \text { (and hence } m(t) \text { ). }\end{array}$ & $\begin{array}{l}\text { The discussion under prediction } 3 \text { ) (column } \\
\text { to the left) suggests that individuals may } \\
\text { slow their effective health deterioration as } \\
\text { they age and begin to consume medical care. }\end{array}$ \\
\hline $\begin{array}{l}\text { 5) Medical care } \\
\text { increases } \\
\text { discontinuously when } \\
\text { individuals become } \\
\text { unhealthy. }\end{array}$ & $\begin{array}{l}\text { Dynamics are not } \\
\text { characterized by regime } \\
\text { switches and medical care } \\
\text { changes gradually. }\end{array}$ & $\begin{array}{l}\text { Healthy people do not consume } \\
\text { medical care. When, their health } \\
\text { reaches the health threshold they } \\
\text { abruptly (discontinuously) begin } \\
\text { to consume medical care. }\end{array}$ & $\begin{array}{l}\text { Moderate support for the notion of a regime } \\
\text { switch is provided by Grossman's (1972a; } \\
\text { chapter V, p. 56) observation that over two } \\
\text { thirds of the NORC sample reported no sick } \\
\text { days, and “... Since the characteristics of } \\
\text { these two groups [reporting sick days and } \\
\text { no sick days] are very similar, it is difficult } \\
\text { to explain the behavior of the [group that } \\
\text { had no sick days]. Put differently, the two } \\
\text { groups essentially represent "two different } \\
\text { samples," and problems arise when the data } \\
\text { are pooled..." }\end{array}$ \\
\hline $\begin{array}{l}\text { 6) Blue collar workers } \\
\text { let their health } \\
\text { deteriorate faster and to } \\
\text { lower levels. }\end{array}$ & $\begin{array}{l}\text { Blue collar workers have } \\
\text { lower levels of health (see } \\
\text { equation 24) }{ }^{c} \text { The } \\
\text { traditional Grossman } \\
\text { solution is not predictive of } \\
\text { the effective rate } \dot{H}(t) \text { of } \\
\text { blue versus white collar } \\
\text { workers. } d\end{array}$ & $\begin{array}{l}\text { Initially, while healthy, a blue } \\
\text { collar worker's health deteriorates } \\
\text { faster as a result of physically } \\
\text { demanding work and unhealthy } \\
\text { working environments (see } \\
\text { equation } 28){ }^{d} \text { The health of blue } \\
\text { collar workers deteriorates to } \\
\text { lower levels as their health }\end{array}$ & $\begin{array}{l}\text { Those employed in manual occupations have } \\
\text { worse health than those who work in } \\
\text { professional occupations and the health of } \\
\text { women and men in the bottom income } \\
\text { quartile deteriorates much faster than that of } \\
\text { the top income quartile (e.g., Case and } \\
\text { Deaton, 2005; Cutler et al. 2008; Smith, } \\
\text { 1999, 2004, 2007; Van Kippersluis et al. }\end{array}$ \\
\hline
\end{tabular}




\begin{tabular}{|c|c|c|c|}
\hline Prediction & “Optimal” stock & Health threshold & Empirical literature \\
\hline & & $\begin{array}{l}\text { threshold is lower (see discussion } \\
\text { in row above). }\end{array}$ & $\begin{array}{l}2008,2009) \text {. Generally speaking blue collar } \\
\text { workers are found to be in worse health than } \\
\text { white collar workers. }\end{array}$ \\
\hline $\begin{array}{l}\text { 7) The relationship } \\
\text { between education and } \\
\text { health is expected to be } \\
\text { positive and differs for } \\
\text { healthy and unhealthy } \\
\text { individuals. }\end{array}$ & $\begin{array}{l}\text { Health and education are } \\
\text { positively related if the } \\
\text { efficiency of medical care } \\
\text { increases with education } \\
\text { and if the rate of } \\
\text { deterioration decreases with } \\
\text { education (i.e., education is } \\
\text { part of the vector } \mathbf{X}(t) \text {; } \\
\text { equation } 24) \text {. Both effects } \\
\text { cannot be separated in the } \\
\text { "traditional" solution of the } \\
\text { Grossman model. }\end{array}$ & $\begin{array}{l}\text { Initially while individuals are } \\
\text { healthy any relationship between } \\
\text { health and education (see } \\
\text { equation } 28 \text { ) works only through } \\
\text { the effect (if any) of education on } \\
\text { the rate of deterioration. After } \\
\text { individuals reach the health } \\
\text { "threshold" both pathways } \\
\text { (through the presumed increased } \\
\text { efficiency of medical care usage } \\
\text { and through any affect on the rate } \\
\text { of deterioration) are relevant. By } \\
\text { comparing healthy with unhealthy } \\
\text { individuals both effects can be } \\
\text { separately analyzed. }\end{array}$ & $\begin{array}{l}\text { A strong positive association between } \\
\text { education and health has been established in } \\
\text { the empirical literature. To the best of our } \\
\text { knowledge the literature has not yet made an } \\
\text { attempt to test the interpretation of the } \\
\text { Grossman model advocated here, i.e., to } \\
\text { distinguish between healthy and unhealthy } \\
\text { individuals and test differences in their } \\
\text { respective relationships between health and } \\
\text { education. The empirical test is described in } \\
\text { Section 3. }\end{array}$ \\
\hline
\end{tabular}

$a_{\varepsilon}>0$ is required to reproduce other empirical findings; see note a in Table 2;

${ }^{b}$ Note the distinction between the effective health deterioration rate $\dot{\mathrm{H}}(\mathrm{t})$ and the "natural" health deterioration rate $\mathrm{d}(\mathrm{t})$;

cBlue collar workers are broadly defined as individuals who generally have 1) lower levels of education, 2) lower wages, and 3) perform "hard" labor (e.g., construction). As a result of "hard" labor and worse working environments blue collar workers are believed to be characterized by higher "natural" health deterioration rates d(t) than white collar workers (e.g., Case and Deaton, 2005; Muurinen and Le Grand, 1985);

${ }^{d}$ Assuming wages $\mathrm{w}(\mathrm{t})$, medical prices $\mathrm{pm}(\mathrm{t})$ and environmental variables $\mathbf{X}(\mathrm{t})$ are relatively constant with age $\mathrm{t}$ we have $\dot{\mathrm{H}}(\mathrm{t}) \alpha-\varepsilon(\beta 3+\beta 6) \mathrm{H}(\mathrm{t})$ From this it is not immediately obvious that the effective health deterioration rate would be different for blue versus white collar workers, though $\beta 3$ (the exponential rate of decay of $\mathrm{d}(\mathrm{t})$; see equation 23), may be higher for blue collar workers (but see Case and Deaton, 2005). 